\title{
The Isolation and Identification of Stress Tolerance Ethanol- fermenting Yeasts from Mozzarella Cheese Whey
}

\author{
Gemilang Lara Utama\#, Tb.Benito, A. Kurnani”, ${ }^{\#}$ Sunardi $^{\#}$, Roostita L. Balia ${ }^{\#}$ \\ \# Postgraduate Program on Environmental Science, Universitas Padjadjaran \\ E-mail: lugemilang@gmail.com;g.l.utama@unpad.ac.id
}

\begin{abstract}
Bioethanol conversions has long been considered as a possible solution for whey utilization. The existence of wild ethanolfermenting yeasts that able to hydrolyze lactose become an important thing. Aims of the research was to isolate and identified the potential ethanol-fermenting yeasts from mozzarella cheese whey. Research done experimentally and analyzed descriptively. Yeast candidates isolated from mozarella cheese whey with pour plate method and purified on Potato Dextrose Agar (PDA) with the addition of 3\% Yeast Extract and $10 \mathrm{ppm}$ of Amoxycillin. The candidates were tested to stress tolerance towards various sugar and ethanol contents. Ethanol-fermenting yeast candidates tested in converting whey into bioethanol by inoculating $2 \%$ isolates into mozzarella cheese whey and incubated in room temperature $\left(26-28^{\circ} \mathrm{C}\right)$ for 48 hours, then the ethanol contents tested by Gas Chromatography. The isolate that gave the highest ethanol contents identified using RapID Yeast Plus System. Results showed that there are $5.8 \times 10^{5} \mathrm{cfu} / \mathrm{ml}$ yeasts population in mozzarella cheese whey with four isolates that has different macroscopic character. Four candidate showed endurance towards $30 \%$ sugar and $20 \%$ ethanol contents and isolate W2 chosen as best isolate that produce the highest ethanol contents of $1,515.973$ ppm. RapID Yeast Plus System has identified the isolate W2 has $96.43 \%$ similarity with Candida lambica.
\end{abstract}

Keywords - ethanol, identification, isolation, mozzarella cheese whey, yeasts

\section{INTRODUCTION}

Bio-conversions of cheese whey into ethanol becoming an interesting alternative for reducing the amount of pollutant disposal into the environment. Whey utilization could reduce disposal of high organic matter into stream which manifested in biochemical oxygen demand (BOD) of 30-50 g/L and chemical oxygen demand (COD) of 60-80 g/L with lactose as the most part that responsible for it [1][2]. The future trend for cheese factories is to move towards zero discharge, i.e., move away from high disposal costs and find more environmentally friendly and profitable applications such as fermenting lactose [3]. Although rare, lactose fermentation to ethanol could be done by yeasts. Kluyveromyces spp. and Candida spp. was the popular yeasts that could ferment lactose into ethanol [1][5][6]. Saccharomyces cerevisiae was a frequently used yeast in ethanol producing process because the good fermentative capacity and ethanol tolerance that allowing to produce up to $20 \%(\mathrm{v} / \mathrm{v})$ ethanol, however wild S.cerevisiae strain are unable to metabolise lactose [9]. The search of other lactose to ethanol fermenting yeasts, especially wild yeasts that has endurance towards high ethanol stress were still done to enhance the results [1].
Diversity of wild yeasts in cheese whey will depend on the cheese production process. One of the most cheese produced in recent years is mozzarella cheese which using chymosin and lactic acid culture in their cheese-making process [10]. Previous research showed several yeasts with specific capability originally isolated from chesees and milk products, has capability in utilizing variety of milk components and its derivatives as growth substrates [11]. Many of yeasts strain with ethanol fermenting capabilities such as S. cerevisiae, K. Marxianus, K. lactis, C. Kefyr and C. Sphaerica was found in mozzarella cheese which is possible become residues in their whey [13].

Aims of the research was to isolate and identify the potential ethanol-fermenting yeasts from mozzarella cheese whey. Meanwhile, the tolerance of high ethanol and sugar concentrations are important characteristics that should be possessed by yeasts for industrial ethanol production [14]. Therefore, yeasts ability in producing ethanol determined and the resistance towards high ethanol and sugar concentration also tested. Chosen isolate that produced highest ethanol content and has ability to tolerate high ethanol and sugar content were identified with RapID Yeasts Plus System. 


\section{MATERIALS AND METHODS}

Mozzarella cheese whey taken from Koperasi Peternak Bandung Selatan (KPBS), Pangalengan, Bandung District. Isolation and purification of yeasts used Potato Dextrose Agar/PDA (Oxoid Ltd.), 3\% Yeast Extract/YE (Kraft Foods) and amoxycillin. Nutrient Broth/NB (Oxoid Ltd.), Glucose monohydrate (Oxoid Ltd) and ethanol used to determined yeasts tolerance towards high sugar and ethanol. RapID Yeast Plus System (Remel Inc.) used to identify of the best yeast isolate that produce highest ethanol contents.

Total yeasts population of mozarella cheese whey identified with pour plate method at room temperature (26$28^{\circ} \mathrm{C}$ ) incubation for 48 hours and counted with total plate count method, then different morphological yeasts appear was identified. Yeasts candidate streaked and purified on PDA with the addition of $3 \%$ YE and $10 \mathrm{ppm}$ of Amoxycillin [15]. To determine the isolates endurance toward stress condition, the candidates were tested on the media (NB with the addition of 3\% YE and $10 \mathrm{ppm}$ amoxycillin) with various sugar percentage $(10 \%, 20 \%, 30 \%)$ or various ethanol contents $(5 \%, 10 \%, 15 \%, 20 \%)$ then incubated 48 hours in room temperature $\left(26-28^{\circ} \mathrm{C}\right)$, sediment formation observed qualitatively [16].
Candidates capability in producing bioethanol from whey tested by inoculating $2 \%$ isolates into mozzarella cheese whey and incubated in room temperature $\left(26-28^{\circ} \mathrm{C}\right)$ for 48 hours, then the ethanol contents tested by Gas Chromatography. Yeast isolate that produce highest ethanol contents identified using RapID Yeast Plus System [17].

\section{RESULTS AND DISCUSSIONS}

\section{A. Characterization of yeasts isolated from mozzarella cheese whey}

The results showed that there are $5.8 \times 10^{5} \mathrm{cfu} / \mathrm{ml}$ total yeasts population with four yeast-like microorganisms isolated from mozzarella cheese whey which shown in table 1. Yeast-like microoganisms survived at modified media with $10 \mathrm{ppm}$ amoxycillin addition. All identified yeast-like microorganisms designated as $\mathrm{W} 1, \mathrm{~W} 2, \mathrm{~W} 3$ and $\mathrm{W} 4$ carried on the basis of their morphological characteristic. Morphological criteria include the appearace of the cell including color, colony form, size and physiological ability in surviving antibiotic presence on the media [18].

TABLE I

YEAST-LIKE MICROORGANISMS ISOLATED FROM MOZZARELLA WHEY

\begin{tabular}{|c|c|c|c|c|c|}
\hline Isolate & +2 & Colony Form & $\begin{array}{c}\text { Size } \\
(\mu \mathrm{m})\end{array}$ & Macroscopic Colony Form & Microscopic Colony Form \\
\hline W1 & white, flat & round & 7.37 & & \\
\hline W2 & white, shiny & irregular & 5.7 & & \\
\hline W3 & White & thin & 4.56 & & \\
\hline W4 & transparent white, shiny & slimy & 5.66 & & 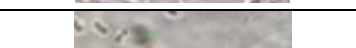 \\
\hline
\end{tabular}

Yeasts is ubiquitous in the environment, especially in sugary and nutritious substrates such mozzarella cheese whey [14]. The presence of yeasts on mozzarella cheese whey showed that yeasts were able to utilize all of the nutritions remains. Cheese whey still contained nutritions such lactose, protein, fat, and mineral that can be utilize for yeasts growth [19]. Yeasts have main mechanisms such as lactose fermentations, lactic acid utilization, lipolytic and proteolytic activities to survive in cheese and their derivatives products such whey [21].
As same as other microorganisms, yeasts need enough nutrition and conducive environment to support their growth. Aside from carbohydrates, yeasts also utilize carbon from citric acid, lactic acid, malic acid, succinic acid and tartaric acid resulting from fermentation. The main source of nitrogen for yeasts growth were ammonia, amino acid, peptide, pepton and other soluble proteins. Yeasts also require other substances such as vitamins and minerals for growth, albeit in small quantities. Some vitamins were often used for yeast growth is biotin, riboflavin, niacin and 
thiamin. Iron (Fe), Cuprum (Cu), Kalium (K), Zinc (Zn) and Iodium (I) was minerals that used for yeasts growth [22].

\section{B. Yeast tolerance toward high sugars and ethanol concentrations}

Yeasts ability in tolerate high sugar and ethanol concentrations shown at table 2 . The result showed that all of the yeast-like microorganisms chosen (W1, W2, W3 and
W4) were able to tolerate sugar concentration until $30 \%$ and ethanol concentration until $20 \%$. High sugar and ethanol tolerance were qualitatively shown by sediment formed on the media. The decrease of sediment formed in line with sugar concentrations escalation and the increase of ethanol concentration.

TABLE III

QUALITATIVE TEST OF YEASTS TOLERANCE TOWARDS HIGH SUGARS AND ETHANOL CONCENTRATION

\begin{tabular}{|c|ccc|cccc|}
\hline \multirow{2}{*}{ Isolates } & \multicolumn{3}{|c|}{ Sugar Concentration } & \multicolumn{3}{c|}{ Ethanol Concentrations } \\
\cline { 2 - 9 } & $\mathbf{1 0 \%}$ & $\mathbf{2 0 \%}$ & $\mathbf{3 0 \%}$ & $\mathbf{5 \%}$ & $\mathbf{1 0 \%}$ & $\mathbf{1 5 \%}$ & $\mathbf{2 0 \%}$ \\
\hline W1 & +++ & ++ & + & ++++ & +++ & ++ & ++ \\
\hline W2 & +++ & ++ & + & +++ & +++ & ++ & ++ \\
\hline W3 & +++ & ++ & ++ & +++ & ++ & ++ & ++ \\
\hline W4 & +++ & ++ & ++ & +++++ & ++++ & +++ & + \\
\hline
\end{tabular}

$++++=$ very good growth,$+++=$ good growth,$++=$ weak growth,$+=$ feeble growth

The presence of sugar is one of the factor that can increase or delay yeast growth. Different kind of sugar gave various effect such as fructose that gave inhibition effect thru increasing ethanol toxicity activity toward yeast, while glucose were more supportive for ethanol production up to $15 \%$ concentration [8]. Previous research reported that sugar concentrations from 20 to $30 \%$ decreased yeast growth rate as shown in sediment formed decrease by all of the isolates [24]. Higher sugar concentrations resulting in higher osmotic pressure that cause lowest growth rate of yeasts [25]. Yeast can be survived on high sugar concentration substrates which mean has a high osmotic pressure through synthesis and retention of glycerol [26].

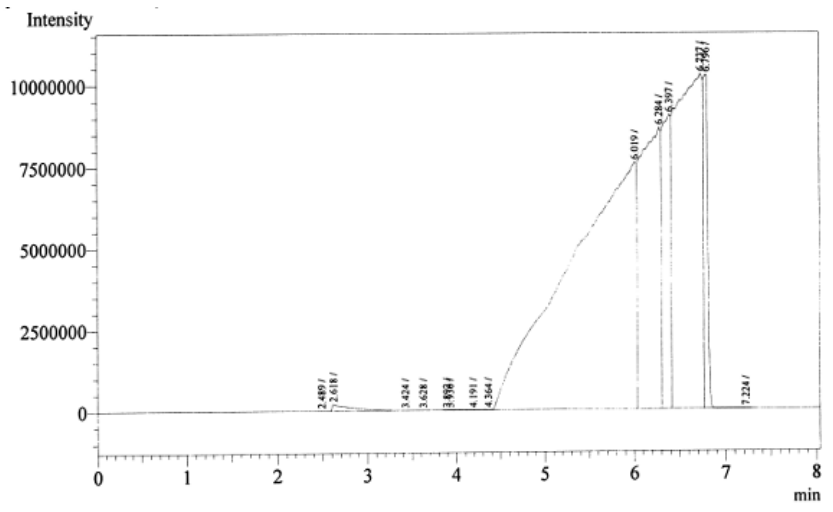

(a)

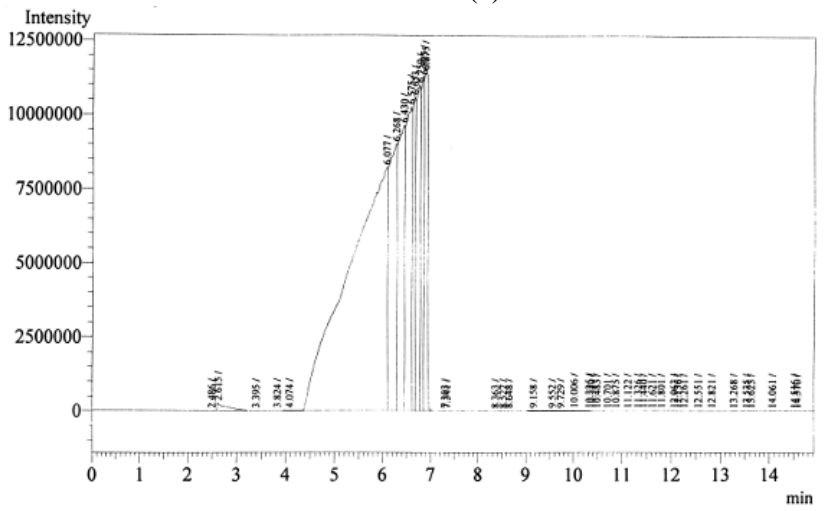

(c)
Ethanol is hazardous for yeasts because it can be role in inhibiting growth along with the increase of concentration [27]. The presence of ethanol can damages mitochondrial DNA in yeast cells and cause inactivation of hexokinase and dehydrogenase enzyme [28]. Ethanol impaired cellular wall permeability disrupting sorting and signaling function so that decreases growth rates, fermentation rates and cell viability of yeasts [7], however there are seven yeasts that have ability to tolerate ethanol until $12 \%$ concentration and some other yeasts has ability to tolerate ethanol until 14\% [14]. Previous study found that yeasts isolated from orchard soil isolates could tolerate $20 \%$ ethanol concentration, same with yeast-like microorganisms originally from mozzarella cheese whey as shown on table 2 [29].

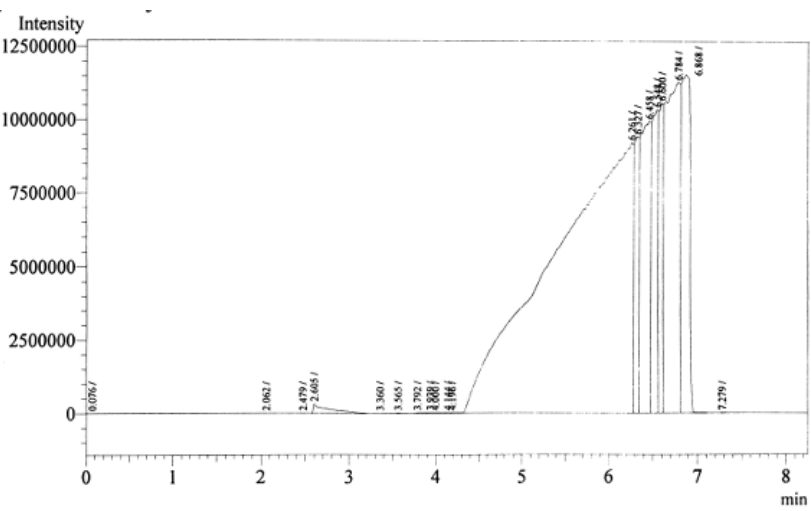

(b)

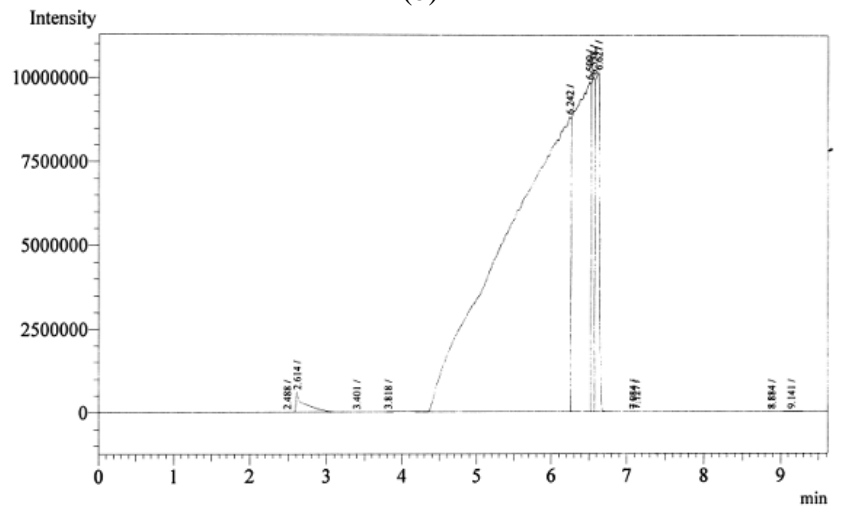

(d)

Fig 1. The results of gas chromatography of ethanol concentration produced from mozzarella whey fermentation by isolates W1 (a), W2 (b), W3 (c) and W4 (d) 


\section{Ethanol production}

Ethanol concentrations resulting from mozzarella cheese whey fermentation by indigenous yeasts shown by Figure 1 and Table 3. The highest ethanol content produced by isolates W2 with 1,515,973 ppm ethanol contents. The results on Figure 1 (a) showed that ethanol produced by isolates $\mathrm{W} 1$ detected on peak number 2 with 2.618 minutes retention time with resulting area intensity of 3,003,28. Figure 1 (b) detected the ethanol produced by isolates W2 on peak number 2 with 2.613 minutes retention time with area intensity of $3,814,46$. Figure 1 (c) showed that ethanol produced by isolates W3 detected on peak number 2 with 2.615 minutes retention time with area intensity of 3,308,11. Meanwhile isolates W4 shown area intensity of 4,598,64 which detected on peak number 2 with 2.614 minutes retention time.

TABLE IIIII

ETHANOL CONCENTRATION

\begin{tabular}{cccccc}
\hline Isolate & Area & $\begin{array}{c}\text { Conc. } \\
\boldsymbol{\mu g} / \mathbf{m l}\end{array}$ & $\begin{array}{c}\text { Dilu- } \\
\text { tion } \\
\mathbf{m L}\end{array}$ & $\begin{array}{c}\text { Vol. } \\
\text { Sample } \\
\mathbf{m L}\end{array}$ & $\begin{array}{c}\text { Ethanol } \\
(\mathbf{p p m})\end{array}$ \\
\hline W1 & $3,003,28$ & $4,891.75$ & 7 & 50 & 684.845 \\
\hline W2 & $3,814,46$ & $6,213.00$ & 12.2 & 50 & $1,515.973$ \\
\hline W3 & $3,308,11$ & $5,388.26$ & 9.1 & 50 & 980.663 \\
\hline W4 & $4,598,64$ & $7,490.29$ & 8.7 & 50 & $1,303.31$ \\
\hline
\end{tabular}

Microorganisms' ethanol production resulted from long chain metabolic reactions. The main metabolic process is glycolysis, a series of enzyme-catalyzed reactions that convert glucose into pyruvate in order to generate the energy and reducing equivalents required for driving downstream cellular activity such as ethanol production [12].

The process of ethanol formation by yeast, made through the utilization of existing carbon source in a substrate. However, not all yeasts species have the same ability to hydrolize specific carbon source contained in substrate. As in whey, yeast must have the ability to hydrolize lactose. Several types of yeast are less effective in hydrolyze lactose so it can not perform advanced fermentation and form ethanol. This is because yeast lactase activity was so weak, so that lactose can not be utilized perfectly. Under optimum conditions, the yeast can produce $0.5 \mathrm{~g}$ ethanol of $1 \mathrm{~g}$ of lactose [19]. The ethanol-fermenting yeasts posessed proteolytic but not lipolytic activities, produced low amounts of sulphur dioxide and hydrogen sulphide and different quantities of higher ethanols, ethyl acetate and acetaldehyde depending on the species and strains [30].

Lactose fermentation to ethanol can be done by several kinds of yeast. Kluyveromyces spp. and Candida spp. was popular yeast that can ferment lactose into ethanol [1][2][6][23]. Saccharomyces cerevisiae is the yeast that often used in the production of ethanol because has good fermentation capacity and tolerance toward ethanol so it could produce ethanol until $20 \%$ (v/v), however wild S.cerevisiae strain was not able to utilize lactose for metabolism [9]. The quest of wild yeast that has the ability to ferment ethanol from lactose continues to be done, especially for yeast that has resistance toward high ethanol concentrations with the goal of improving the existing results [1]. Efficient bioethanol fermentation requires the selection of superior strains that are capable of ethanol stress tolerance [20].

\section{Yeast Identification}

The preliminary tests of yeasts tolerance towards sugar and alcohol with the ability to produce ethanol resulting 1 best isolates with the highest ethanol production. Isolates W2 was the best mozzarella cheese whey indigenous yeast with the ability to survive in the sugar content of $30 \%$, tolerate $20 \%$ alcohol content and produce bioethanol amounted to $1,515.973 \mathrm{ppm}$.

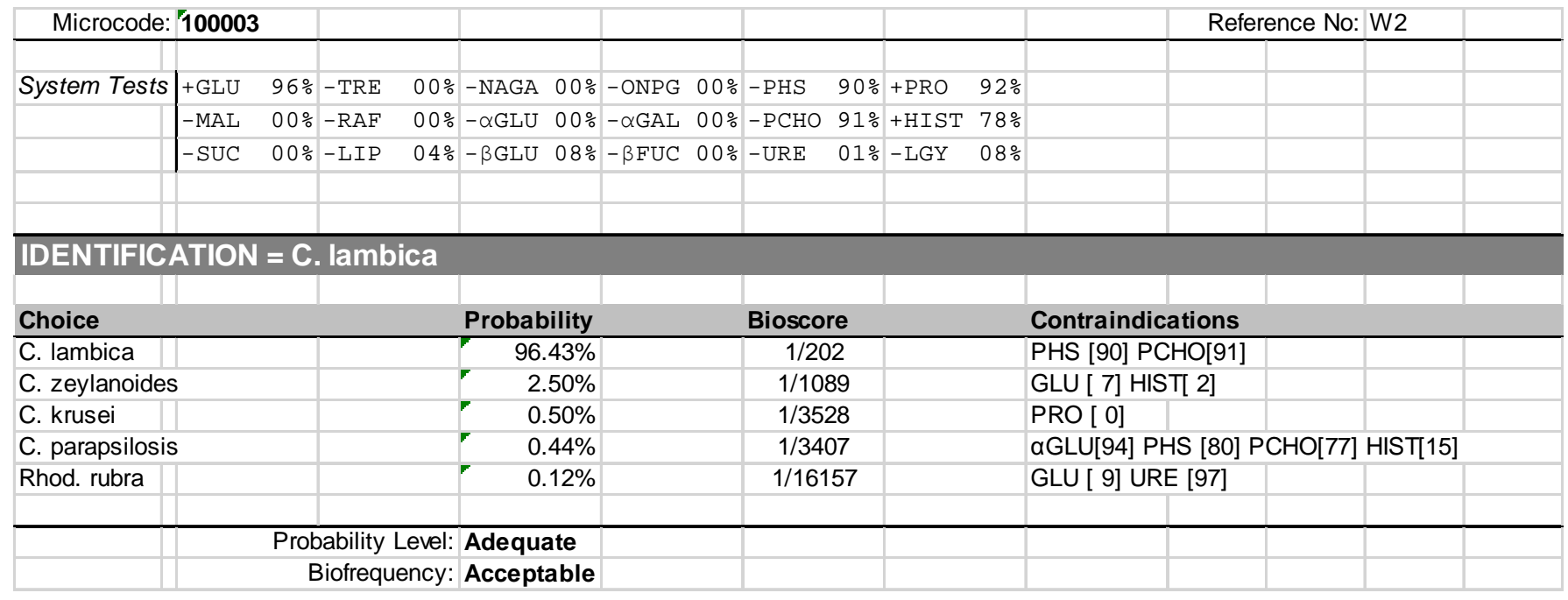

Fig 2. Identification result of Isolates W2 with RapID Yeast Plus System

The result of yeast identification with the Rapid Yeast Plus System states that yeast isolates W2 has similar characteristics to $96.43 \%$ with Candida lambica. Isolates were identified as Candida lambica having the ability to utilize glucose as a source of energy and able to perform enzymatic hydrolysis of arylamide substrate releases free $\beta$ naphtylamide on proline and histidine. As mentioned on the 
previous research, Candida lambica has ability to fement and assimilate glucose and also resulting ethanol, with ability to tolerate glucose until 50\% concentration [4].

Previous research states that some yeasts isolated from cheese whey and dairy products, have the ability to utilize various components of milk and its various derivatives as nutrients for growth [11]. Some kinds of yeast with ethanol fermentation capabilities such as $S$. cerevisiae, K. Marxianus, $K$. lactis, and C. sphaerica, C. kefyr found in mozzarella cheese that can also left in their whey [13].

Referring to the preliminary results, selected yeast strains were also have the ability to tolerate high levels of sugar and ethanol stress. Candida lambica known to have the ability to produce fatty acids in the phospholipids cell wall to overcome the environment stress. In these conditions, tributirin, lecithin and behenic acid is produced to form the cell wall coating layer to replace fat that lost by lipolytic process and osmotic pressure that arises, so that C.lambica was able to survive [31].

Some studies states that Candida spp. has ability to ferment lactose. Candida pseudotropicalis to be the most effective in converting lactose to ethanol [32]. However $C$. Pseudotropicalis cannot survive on high concentration of lactose and ethanol. Utilization of whey by Candida spp. Can be done by considering nutrient, lactose concentrations (5-20\%), micro-aeration and also can be done in batch fermentation that can produce ethanol from 4.1 to $5.8 \%$ [33]. Candida lambica was type of yeast that commonly combined with other yeast for alcoholic products fermentation such as wine [34]. The ability to tolerate environmental stresses support C.lambica to produce ethanol from lactose nicely. This is in line with the results in Table 3, which shows that C.lambica produce the highest ethanol concentrations compared to other isolates.

\section{CONCLUSIONS}

The isolation and identification of potential ethanolfermenting yeasts from mozzarella cheese whey has shown four potential yeast-like isolates. All of the yeast-like isolates has tolerance of sugar concentrations until 30\% and ethanol concentrations until 20\%. The best isolates was isolates W2 that could produce 1,515.973 ppm ethanol and identification with RapID Yeasts Plus System showed that the isolates has $96.43 \%$ similarity with Candida lambica.

\section{ACKNOWLEDGMENT}

Author would like to thank Beasiswa Unggulan BPKLN Diknas for the doctoral program scholarship and West Java province for the research grant. Acknowledges support by Ir. Heri Hidayat from KPBS, the research laboratory of Faculty of Animal Husbandry and the laboratory of food microbiology of Faculty of Agro-industrial Technology, Universitas Padjadjaran who give full access for the research accomplishment

\section{REFERENCES}

[1] Guimarães, P.M.R., Teixeira, J.A. \& Domingues, L. Fermentation of lactose to bioethanol by yeasts as part of integrated solutions for the valorisation of cheese whey, Biotechnology Advances. 28:375-384, 2010.
[2] Spalatelu, C. Biotechnological valorisation of whey. Innovative Romanian Food Biotechnology. 10 (3):1-8, 2012.

[3] Pisano, I., Agrimi, G., Grosso, G., Mena M. C., Ricci, M.A., and Plmieri, L. Improved Saccharomyces cereviseae growth on cheese whey by controlling enzymatic lactose hydrolisis. Chemical Engineering Transactions. 43:637-642. 2015.

[4] Jamili, Yanti, N.A. and Susilowati, P. E. Diversity and the role of yeast in spontaneous cocoa bean fermentation from Southeast Sulawesi, Indonesia. Biodiversitas. 17 (1):90-95. 2016.

[5] Spalatelu, C. and Coman, G. Study of some yeast strains in order to be used for ethanol production from whey. Journal of Agroalimentary Processes and Technologies. 18 (3), 247-252, 2012.

[6] Tipteerasri T, Hanmoungjai W., and Hanmoungjai P. Ethanol Production from Crude Whey by Kluyveromyces marxianus TISTR 5695. FerVAAP Conference, 2007.

$<$ fervaap.kku.ac.th/inter/images/Fervaap2007/.../P2-3.pdf>.

[7] Navarro-Tapia, E., Nana, R. K., Querol, A. And Perez-Tornado, R. Ethanol cellular defence induce unfolded protein response in yeast. Frontiers in Microbiology. 7 (2):1-12.2016

[8] Torre-Gonzalez, F.J., Narvaez-Zapata, J. A., Lopez-y-Lopez, V. E., Larralde-Corona, C. P. Ethanol tolerance is decreased by fructose in Saccharomyces and non-Saccharomyces yeasts. LWT-Food Science and Technology. 67:1-7.2016.

[9] Guimarães, P.M.R., François, J., Parrou, J.L., Teixeira, J.A., Domingues, L. 2008. Adaptive evolution of a lactose-consuming Saccharomyces cerevisiae recombinant. Appl. Environ. Microbiol. 74:1748-56.

[10] Abd El-Gawad, M.A.M. and Ahmed, N. S. Cheese yield as affected by some parameters. Acta Sci. Pol., Technol. Aliment. 10 (2): 131153. 2011.

[11] Roostita, L.B., Fleet, G.H., Putranto, W.S., Mustopa, A.Z., and Utama, G.L. Determination of Yeasts Antimicrobial Activity in Milk and Meat Products. Advance Journal of Food Science and Technology. 3(6):442-445, 2011.

[12] Akinosho, H., Rydzak, T., Borole, A., Ragauskas, A., and Close, D. Toxicological challenges to microbial bioethanol production and strategies for improved tolerance. Ecotoxicology. September 2015.

[13] Suzzi, G., Lombardi, A., Lanorte, M.T., Caruso, M., Andrighetto, C. and Gardini, F. Phenotypic and genotypic diversity of yeasts isolated from water-buffalo Mozzarella cheese. Journal of Applied Microbiology. 88:117-123, 2000.

[14] Tikka, C., Osuru, H.P., Atluri, N., Raghavulu, P.C.V., Kumar yellapu, N., Mannur, I.S., Aluru, P.S., Varma, N.K., Bhaskar, M. Isolation and characterization of ethanol tolerant yeast strains. Bioinformation. 9(8):421-425, 2013.

[15] Akpa, J.G. Modelling of a bioreactor for the fermentation of palmwine by Saccharomyces cereviseae (yeast) and Lactobacillus (bacteria). American Journal of Scientific and Industrial Research. 3 (4):231-240, 2012.

[16] Fakruddin, M., Islam, M.A., Ahmed, M.M., Chowdhury, N. Process Optimization of Bioethanol Production by Stress Tolerant Yeasts Isolated From Agro-Industrial Waste. International Journal of Renewable and Sustainable Energy. 2 (4): 133-139, 2013.

[17] Sanguinetti, M., Porta, R., Sali, M., La Sorda, M., Pecorini, G., Fadda, G. and Posteraro, B. Evaluation of VITEK 2 and RapID Yeast Plus System for Yeast Species Identification: Experience at a Large Clinical Microbiology Laboratory. Journal of Clinical Microbiology. 45 (4):1343-1346, 2007.

[18] Kebbouche-Gana, S. and Gana, M.L. Algerian yeast strain, identification and roduction of single cell protein from whey with strain Candida kefyr. International Journal of Bioscience, Biochemistry and Bioinformatics. 4 (3): 160-165, 2014.

[19] Oreopoulou, V and Russ, W. Utilization of By-Products and Treatment of Waste in the Food Industry. Springer Publisher. 2007.

[20] Shalsh, F. J., Ibrahim, N.A. and Arifullah, M. Screening of ethanoltolerant fusants of Saccharomyces cerevieae and Pichia stiptis from protoplast fusion. Current Research Journal of Biological Sciences. 8(1):10-14. 2016.

[21] Tudor, D.A., Board, R.G. Food spoilage yeasts. In: The Yeast. Yeasts Technology (Rose, A.H., Harrison, J.S. Eds). $2^{\text {nd }}$ ed. Academic Press, London, 5: 436-451, 2010.

[22] Flores, C.L., Rodriguez, C., Petit, T. and Gancedo C. Carbohydrate and Energy-Yielding Metabolisme in Non-Conventional Yeasts. FEMS Microbiology Rev. 24:507-529, 2000.

[23] Yousef, E.T. Utilization of whey as one dairy industrial waste in the production of alcohol. International Journal of Current Microbiology and Applied Sciences. 4(7):224-228. 2015. 
[24] D’Amato, D., Corbo, M.R., Del Nobile, M.A., Sinigaglia, M. Effects of temperature, ammonium and glucose concentrations on yeast growth in a model wine system. International Journal of Food Science \& Technology. 41: 1152-1157, 2006.

[25] Arroyo-Lopez, F.N., Orlic, S., Querol, A. And Barrio, E. Effects of temperature, $\mathrm{pH}$ and sugar concentration on the growth parameters of Saccharomyces cereviseae, S. kudriavzevii and their interspecific hybrid. International Journal of Food Microbiology. 131:120-127, 2009.

[26] Myers, D.K., Lawlor, D.T.M. and Attfield, P.V. Influence of invertase activity and glycerol synthesis and retention on fermentation of media with a high sugar concentration by Saccharomyces cerevisiae. Applied and Environmental Microbiology. 63: 145-150, 1997.

[27] Ali, M.N. and Khan, M.M. Screening, identification and characterization of alcohol tolerant potential bioethanol producing yeasts. Current Research in Microbiology and Biotechnology. 2(1):316-324, 2014.

[28] Ibeas, J.I., and Jimenez, J. Mitochondrial DNA loss caused by ethanol in Saccharomyces cerevisiae flour yeasts. Appl. Environ Microbiol. 63: 7-12, 1997.
[29] Moneke, A.N., Okolo, B.N., Nweke A.I., Ezeogu, L.I. and Ire, F.S Selection and characterization of high ethanol tolerant Saccharomyces yeasts from orchard soil. African Journal of Biotechnology. 7 (24): 4567-4575, 2008.

[30] Suzzi, G., Gardini, F., Lanorte, M.T., Caruso, M.C. and Fiore, C. A survey of yeasts isolated from water-buffalo mozzarella cheese produced in Basilicata. Proceeding of the symposium 'Yeasts in the dairy industry: positive and negative aspects' 2-3 September 1996, Copenhagen (Denmark). IDFSI 9801, 44-49, 1998.

[31] El Dein, M.M.N. Role of lipids in ethanol tolerance of Candida lambica. Indian Journal of Experimental Biology. 35(1):89-91, 1997.

[32] Ghaly, A.E., and El-Taweel, A.A. Effect of nutrient supplements addition on ethanol production from cheese whey using Candida pseudotropicalis under batch condition. Appl. Biochem. Biotechnol. 53:107-31, 1995.

[33] Ghaly, A.E., and El-Taweel, A.A. Effect of micro-aeration on the growth of Candida pseudotropicalis and production of ethanol during batch fermentation of cheese whey. Bioresour. Technol. 52:203-17, 1995.

[34] Jolly, N.P., Varela, C. and Pretorius, I.S. Not your ordinary yeast non-Saccharomyces yeasts in wine production uncovered. FEMS Yeast Res. 10:1-23, 2013. 